\title{
Changing Patterns of Technology Diffusion in a Collaborative Network
}

\author{
Eun-Jung Han* and Soon-Goo Hong* \\ *Co-creation Innovation Center, Dong-A University, Busan, Korea \\ E-mail:ejhan.biz@gmail.com \\ **Department of Management Information Systems, Dong-A University, Busan, \\ Korea \\ E-mail: shong@dau.ac.kr
}

\begin{abstract}
This study focuses on inter-organizational collaboration to diffuse technology innovation. An ecosystem perspective on innovation takes into account that relationships among organizations are continuously changing and evolving. Thus, this study investigated changes in interaction patterns among organizations involved in the use and distribution of technology innovation. A two-mode network analysis was conducted to determine changes in patterns of technology diffusion in a collaborative network. Centrality measures were longitudinally examined according to the evolutionary time of technology innovation. The results indicate that there are leading entities that drive the connectivity of a network and the influences of these entities changed according to technology innovation. This study sheds light on policy strategies for successful networks in regional innovation.
\end{abstract}

Keywords: Technology Innovation, Ecosystems, Inter-organizational network, Two-mode Network Analysis, Centrality

\section{Introduction}

Technology innovation is a collective process because different organizations are engaged in it, from the technology development stage to its utilization. Therefore, innovation should be implemented through a collaborative network. Recent studies have deal with inter-organizational networks for technology innovation from the perspective of innovation ecosystems [1-3], which emphasizes dynamic changes of inter-organizational networks [4]. Although some theoretical frameworks have been developed to explain the dynamics of collaborative innovation [4-6], few empirical studies have examined longitudinally evolution of collaboration networks [2]. Thus, this study investigated changes in interaction patterns of a collaborative network for technology innovation.

\section{Theoretical Backgrounds}

\subsection{Innovation Ecosystems Approach}

Innovation can be achieved only when economic value is generated from new knowledge or technologies. In this respect, research on innovation has traditionally centered on innovation process that includes technology development, dissemination, and use and adaptation. Studies mostly emphasize inter-organizational collaboration in implementing this process. An emerging perspective of innovation ecosystems takes into account that relationships among organizations involved in innovation are continuously changing $[4,7]$. Innovation ecosystems are characterized by structural dynamics in which inter-organizational relationships evolve according to technological development, market demands, and social contexts that affect diffusion of technology innovation. In other 
words, technology innovation is disseminated through dynamic changes in interactions among organizations involved in the innovation process.

\subsection{Resource Dependency Theory and Service-Dominant (S-D) Logic}

An inter-organizational network can be described by the resource dependency theory, in which all organizations should collaborate with other organizations to share resources. Any organization cannot have all resources by themselves [8]. This perspective is related to S-D logic, which is an emerging theory introduced by Vargo and Lusch [9] to explain dynamic changes in service-driven markets. S-D logic describes that service as the application of resources by its recipients. The value of service is generated when customers use resources that include information, technologies, functions, and products provided by others. Customers obtain value through service embedded in resources.

S-D logic describes a social economy system as a stakeholder network for service exchange. Vargo and Akaka [10] explained that a social economy system is selforganized through the integration of shared resources. They conceptualized the servicedriven inter-organizational networks as service ecosystems. All organizations involved in a service ecosystem collaborate to generate value of the entire system through service exchange. The organizations co-create customers' value by integrating others' resources into their own products or services $[11,12]$. In this respect, this study deals with an innovation ecosystem as a collaboration network for application of resources.

\section{Research Design}

This research investigated evidences for changes in technology diffusion patterns using a longitudinal network analysis. The Digital Living Network Alliance (DLNA) was assessed to demonstrate interaction patterns in a collaborative network around technologies The DLNA is an inter-organizational network of device manufacturers that develops and utilizes technology standards for sharing digital content among multimedia devices. Relational data were obtained for a network analysis, collected by analyzing DLNA certification documents, which include 21,992 products from 144 companies. These data were arranged in a two-mode incidence matrix $(X)$ in which $x i j>0$ if a company $(i)$ provided a product type $(j)$; otherwise, $x i j=0$. This two-mode matrix can be analyzed as a bipartite graph, developed by Borgatti and Everett [13]. Converting twomode data to one-mode data can cause loss of information because of focusing on one of the two modes [14]; thus, a bipartite graph is an alternative approach to assessing both modes of two-mode data. Fig. 1 is a bipartite graph that connects companies and products in the DLNA. This graph was generated by NetDraw, which is network visualization software. 


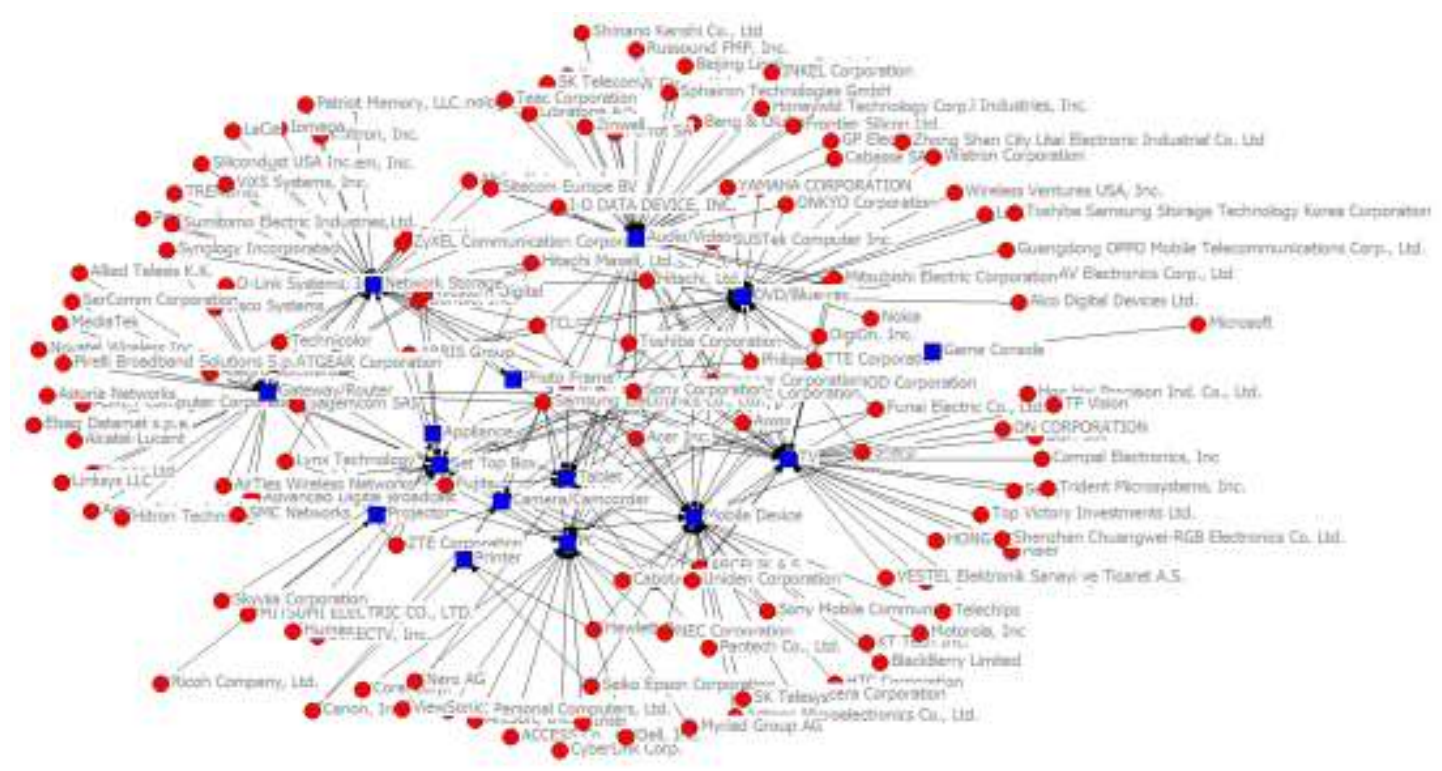

Figure 1. Bipartite Graph of Companies and Product Types

The graphical representation shows the structural relationships among companies and products. In the graph, companies are represented by round nodes and products by square nodes. The graph indicates that companies positioned in the peripheral area are usually specialized in one product type. The companies in the middle of the graph provide different product types. This means that the companies that provide multiple products contribute to the connectivity of the network. This research focused on identifying which companies and product types are centrally located in the network because centrality represents not only the structural importance of a node, but also the connectivity of neighboring nodes [15]. Centrality measures indicate which nodes play important roles in the flow of information and resources [16], and central nodes may be influential, leaders, or gatekeepers that control the structure of resource exchange in a network [14]. Borgatti and Everett [13] explained that two-mode data bipartite graphs allow for the utilization of standard measures of centrality.

In this study, three measures of centrality were examined: degree centrality, closeness, and betweenness. According to Freeman [17], these three centrality concepts can be used to describe a collective process. Degree centrality refers to the influence in the flow of resource exchange. Closeness means the independence of a node from the flow of resource exchange. Betweenness is the control power in the flow of resource exchange. These measures indicates how network structure might affect complexity and productivity [16].

In this study, two-mode network data were divided into three periods according to the improvement of technology standards. Han and Hong [18] pointed out that structural changes of a collaborative network for technology diffusion are driven by innovation of technology standards. Table 1 shows the number of DLNA-certified products based on 15 product types during the three periods of improvement. 


\section{Table 1. The Number of DLNA Certificates for Each Product Type}

\begin{tabular}{crrr}
\hline Time & Period 1 & Period 2 & Period 3 \\
\hline Appliance & - & 4 & 3 \\
Audio/Video & 29 & 144 & 32 \\
Camera/Camcorder & 1 & 16 & 696 \\
DVD/Blue-ray & 16 & 282 & 206 \\
Game Console & 1 & 1 & 1059 \\
Gateway/Router & - & 21 & 1 \\
Mobile Device & 1 & 175 & 336 \\
Network Storage & 24 & 128 & 1486 \\
PC & 554 & 2134 & 215 \\
Photo Frame & - & 2 & 1470 \\
Printer & - & 33 & 5 \\
Projector & - & 1 & 31 \\
Set Top Box & 1 & 12 & 114 \\
Tablet & - & 8 & 50 \\
TV & 54 & 2326 & 149 \\
Total & 681 & 5287 & 10173 \\
\hline
\end{tabular}

The DLNA has developed technology standards over the last decade since introducing a technology guideline version 1.0 in 2004. DLNA standards were improved to the guideline version 2.0 in 2008, which extended the range of DLNA-compatible products. Since 2011, the DLNA has allowed software applications to adopt DLNA standards. Therefore, this longitudinal study investigated changes in the network structure of DLNA technologies. The central nodes of each time-series network were compared to determine changes in the flow of diffusion of technology standards. We used UCINET 6.0 software package was used to analyze the two-mode network.

\section{Results and Findings}

A two-mode network analysis was conducted to investigate the structure of affiliation among companies and product types in the collaborative network for the application of DLNA standards. Centrality measures were longitudinally examined according to the evolutionary time of technology innovation. Table 2 represents the top three companies in the centrality measurements. The influence of these companies in the flow of resource exchange can be explained by comparing the degree of centrality for each company.

Table 2. Top Three Companies based on Centrality Measurements

(a) Degree centrality

\begin{tabular}{cccc}
\hline Ranking & Period 1 & Period 2 & Period 3 \\
\hline \multirow{2}{*}{1} & Sony Corporation & Samsung Electronics & Samsung Electronics \\
& $(0.667)$ & $(0.6)$ & $(0.667)$ \\
2 & Toshiba Corporation & Sony Corporation & Sony Corporation \\
& $(0.333)$ & $(0.533)$ & $(0.667)$ \\
3 & Pioneer Corporation & LG Electronics & Panasonic Corporation \\
& $(0.333)$ & $(0.4)$ & $(0.467)$ \\
\hline
\end{tabular}

\begin{tabular}{cccc} 
(b) Closeness centrality & & \\
\hline Ranking & Period 1 & Period 2 & Period 3 \\
\hline \multirow{2}{*}{1} & Sony Corporation & Sony Corporation & Samsung Electronics \\
& $(1.809)$ & $(0.834)$ & $(0.903)$ \\
2 & DigiOn Inc. & Samsung Electronics & Sony Corporation \\
& $(0.891)$ & $(0.799)$ & $(0.878)$ \\
3 & Toshiba Corporation & LG Electronics & LG Electronics \\
& $(0.803)$ & $(0.716)$ & $(0.789)$ \\
\hline
\end{tabular}

(c) Betweenness centrality

\begin{tabular}{cccc}
\hline Ranking & Period 1 & Period 2 & Period 3 \\
\hline 1 & Sony Corporation & Samsung Electronics & Samsung Electronics
\end{tabular}




\begin{tabular}{cccc}
\hline & $(0.276)$ & $(0.189)$ & $(0.141)$ \\
2 & DigiOn Inc. & Sony Corporation & Sony Corporation \\
& $(0.064)$ & $(0.158)$ & $(0.11)$ \\
3 & Toshiba Corporation & LG Electronics & LG Electronics \\
& $(0.056)$ & $(0.072)$ & $(0.087)$ \\
\hline
\end{tabular}

For the degree centrality, Sony Corporation had the large score over all periods. Particularly, Sony Corporation was ranked first during period one, and there was a greatest difference between the largest degree and others (0.633:0.333:0.333). This means that the connectivity of the network structure during period one was driven by Sony Corporation, which led the technology innovation. During period two, the largest degree was assigned to Samsung Electronics. However, the difference among the degrees decreased (0.6:0.533:0.4). This tendency continued in period three (0.667:0.667:0.467). With respect to the closeness centrality, Sony Corporation had the highest score during periods one and two, and there was a relatively greater difference between the degrees in period one compared to other periods (1.089:0.891:0.803). This indicates that Sony played a leading role in technology diffusion. The differences among the closeness scores decreased over time during period two (0.834:0.799:0.726) and three (0.903:0.878:0.789). Finally, for the betweenness centrality, Sony also led the connectivity of the network structure by mediating between other companies. As the network has evolved, the differences in betweenness values have decreased.

A two-mode, bipartite network analysis enables network data to be examined in both modes. The structure of the DLNA can be viewed in terms of not only companies but product types, for which centrality measurements were examined. Table 3 shows the top three product types based on centrality.

\section{Table 3. Top Three Product Types based on Centrality Measurements}

(a) Degree centrality

\begin{tabular}{cccc}
\hline Ranking & Period 1 & Period 2 & Period 3 \\
\hline \multirow{2}{*}{1} & PC & Network Storage & Projector \\
& $(0.524)$ & $(0.319)$ & $(0.269)$ \\
2 & Audio/Video & Audio/Video & Audio/Video \\
& $(0.429)$ & $(0.319)$ & $(0.269)$ \\
3 & DVD/Blue-ray & TV & Mobile Device \\
& $(0.19)$ & $(0.232)$ & $(0.244)$ \\
\hline
\end{tabular}

(b) Closeness centrality

\begin{tabular}{cccc}
\hline Ranking & Period 1 & Period 2 & Period 3 \\
\hline \multirow{2}{*}{1} & PC & Network Storage & Projector \\
& $(0.787)$ & $(0.503)$ & $(0.462)$ \\
2 & Audio/Video & Audio/Video & Audio/Video \\
& $(0.725)$ & $(0.487)$ & $(0.457)$ \\
3 & DVD/Blue-ray & TV & Mobile Device \\
& $(0.587)$ & $(0.455)$ & $(0.451)$ \\
\hline
\end{tabular}

(c) Betweenness centrality

\begin{tabular}{cccc}
\hline Ranking & Period 1 & Period 2 & Period 3 \\
\hline \multirow{2}{*}{1} & PC & Network Storage & Audio/Video \\
& $(0.411)$ & $(0.503)$ & $(0.252)$ \\
2 & Audio/Video & Audio/Video & Mobile Device \\
& $(0.298)$ & $(0.487)$ & $(0.25)$ \\
3 & DVD/Blue-ray & TV & Projector \\
& $(0.078)$ & $(0.455)$ & $(0.236)$ \\
\hline
\end{tabular}

For the degree centrality during period one, PCs (0.524) and audio/videos $(0.429)$ had much larger values compared to other products $(\leq 0.19)$. During period two, network storages (0.319), audio/videos (0.319), and TVs (0.232) had the largest degrees. During 
period 3, projectors (0.269) and mobile devices (0.269) emerged as the highest ranking products in terms of degree centrality. For both closeness and betweenness centrality measurements, a similar tendency was observed. The dominant product types during period one included PC, audio/video, and DVD/blue-ray. During period two, network storage, audio/video, and TV products played an important roles in the network structure. The most important products during period three were projector, audio/video, and mobile devices. Audio/video products were influential throughout all three periods.

In all the centrality measurements, the differences between the degrees continuously decreased over time, indicating that the network ties between companies or product types more equalized. During the early days of technology innovation, a few dominant actors controlled the flow of information or resource exchange. As technology innovation was disseminated, the number of actors participating in the network increased. The larger the network size, the more its connectivity become equalized.

\section{Conclusions and Discussions}

The results of the longitudinal two-mode network analysis showed how the network structure of technology commercialization has changed and illuminated patterns of technology diffusion. The results indicate that there are leading entities that drive the connectivity of a network, and the influences of these entities changed according to technology innovation.

In the case of the DLNA, the companies that lead to the flow of resource exchange include Sony Corporation, Samsung Electronics, and LG Electronics. These companies, as board members of the DLNA, actually contribute to the evolution of the network by supporting technology development and utilization. With respect to products, the dominant product types that lead technology diffusion have changed according to technology innovation. For example, PCs were the most influential product type during period one, while network storages and TVs played important roles during period two and mobile devices and projectors dominated period three. These results correspond with changes in the media device markets. During the early stage of introducing DLNA technologies, PC manufacturers led technology innovation. As the number of DLNAcertified products increased, network storages (as server) and TVs (as client player) were important devices for building server-client architecture in a home network. Since smartphones emerged, mobile devices and projectors have become readily available for connecting the network of technology diffusion.

This empirical study focused on investigating changes in patterns of technology diffusion by analyzing connections among the companies and products related to technology innovation, the success of which depends on building a network structure for commercialization. This collaborative network evolves according to technology innovation; therefore, the network should be flexible to allow potential actors and products to become involved. These findings provide useful knowledge underpinning policy strategies to build a successful network for regional or national innovation.

This study contributes to the literature on the evolution of innovation ecosystems. Existing research on innovation offers limited descriptions of dynamic changes in social economy systems because it focuses on core factors that influence technology innovation [4]. In the current study, an approach for investigating the dynamics of an industrial structure using a two-mode network analysis was proposed to examine a role which central nodes play in changes to network structures. Different factors that influence network structures should be used in future research that employs various analytical technologies to measure the structure of technology diffusion pattern. 


\section{Acknowledgements}

This work was supported by the Ministry of Education of the Republic of Korea and the National Research Foundation of Korea (NRF-2015S1A3A2046781).

\section{References}

[1] Adner, R. and R. Kapoor, Value creation in innovation ecosystems: how the structure of technological interdependence affects firm performance in new technology generations. Strategic Management Journal, 31(3) 2010, 306-333.

[2] Durst, S. and P. Poutanen, Success factors of innovation ecosystems: A literature review, in COCREATE 2013: The Boundary-Crossing Conference on Co-Design in Innovation, R. Smeds and O. Irrmann, Editors. (2013).

[3] Rubens, N., et al., Leveraging social media for analysis of innovation players and their moves. Innovation Ecosystems Network, Media X, at Stanford University, (2010).

[4] Mercan, B. and D. Göktaş, Components of innovation ecosystems: a cross-country study. International Research Journal of Finance and Economics, 76 (2011), 102-112.

[5] Leydesdorff, L. and M. Meyer, Triple Helix indicators of knowledge-based innovation systems: Introduction to the special issue. Research Policy, 35(10) (2006), 1441-1449.

[6] Carayannis, E.G. and D.F. Campbell, 'Mode 3'and'Quadruple Helix': toward a 21st century fractal innovation ecosystem. International Journal of Technology Management, 46(3-4) (2009), 201-234.

[7] Papaioannou, T., D. Wield, and J. Chataway, Knowledge ecologies and ecosystems? An empirically grounded reflection on recent developments in innovation systems theory, in The 6th International Triple Helix Conference on University-Government-Industry Relations: Singapore. (2007).

[8] Pfeffer, J. and G.R. Salancik, The external control of organizations: A resource dependence perspective, New York: Harper \& Row. (1978).

[9] Vargo, S.L. and R.F. Lusch, Evolving to a New Dominant Logic for Marketing. Journal of Marketing, 68(1) (2004) 1-17.

[10] Vargo, S.L. and M.A. Akaka, Value Cocreation and Service Systems (Re)Formation: A Service Ecosystems View. Service Science, 4(3) (2012), 207-217.

[11] Akaka, M.A., S.L. Vargo, and R.F. Lusch, An Exploration of Networks in Value Cocreation: A ServiceEcosystems View, in Special Issue - Toward a Better Understanding of the Role of Value in Markets and Marketing, Review of Marketing Research, 9(2012), 13-50.

[12] Adner, R., Match your innovation strategy to your innovation ecosystem. Harvard business review, 84(4) (2006), 98-107.

[13] Borgatti, S.P. and M.G. Everett, Network analysis of 2-mode data. Social networks, 19(3) (1997), 243269.

[14] Borgatti, S.P., M.G. Everett, and J.C. Johnson, Analyzing social networks. SAGE Publications Limited. (2013).

[15] Bonacich, P., Power and centrality: A family of measures. American journal of sociology, 92(5) (1987), $1170-1182$.

[16] Mote, J.E., R\&D ecology: using 2-mode network analysis to explore complexity in R\&D environments. Journal of Engineering and Technology Management, 22(1) (2005), 93-111.

[17] Freeman, L.C., Centrality in social networks conceptual clarification. Social networks, 1(3) (1978), 215239.

[18] Han, E. and S. G. Hong, Technology Innovation and Changes on Structural of Value Creation in an Industrial Ecosystem. Journal of Korea Technology Innovation Society, 20(1) (2017), 175-204.

**Corresponding author: Soon-Goo Hong

Department of Management Information Systems,

Dong-A University,

Busan, Korea

E-mail: shong@dau.ac.kr 
International Journal of $\mathrm{u}-$ and $\mathrm{e}-$ Service, Science and Technology Vol.10, No.8 (2017) 